(C) С.А. Маспенников, 2009

УДК 622.28

С.А. Маспенников

МЕТОДИКА ОПРЕДЕЛЕНИЯ РАЦИОНАЛЬНОГО

МОДУПЯ ДЕФОРМАЦИИ БЕТОНА

В КОМБИНИРОВАННОЙ ЧУГУННОБЕТОННОЙ КРЕПИ

Семинар № 18

Б опее широкое применение в поспедние годы комбинированной чугунно-бетонной крепи выдвигает на первый ппан вопросы обеспечения повышения её несушей способности, экономичности и надёжности. Аварийные ситуации в стволах на Текепейском руднике [1], горных предприятиях немецкой угольной и капийной промышленности (отмечено 19 подобных спучаев, ипи 78\% из описанных [2, 3]), многочиспенные спучаи потери герметичности и серьёзных нарушений в стволах, эксппуатируемых в калийной и горнорудной промышленности России (более 13 спучаев $[4,5])$ выявили характерную особенность разрушения такой крепи. После демонтажа нарушенных тюбингов выясняпось, что спой бетона находится в удовлетворительном состоянии. Показателен в этом плане спучай разрушения крепи вентипяционного ствола рудника "Пийло" [6]. После разборки деформированных колец выяснилось, что бетонная часть крепи не разрушипась, т. е. на момент достижения напряжениями в чугуне тюбингов предепьных значений, напряжения в бетоне быпи допустимыми, и разрушения не произошпо, даже при выходе из состояния объёмного сжатия. Учитывая, что объёмная прочность дия бетона в 3-4 раза выше прочности при одноосном сжатии можно сдепать вывод о недостаточном использовании несушей способности бетона в чугунно-бетонной крепи.

Исходя из указанного выше автором предпожно (см. [7, 8]), для повышения несушей способности и снижения материалоёмкости комбинированной чугунно-бетонной крепи, за счёт перераспредепения напряжений между споями равнопропорционально пределу прочности их материалов, применять бетоны с повышенным модулем деформации. При этом для каждого сочетания вида тюбинга, деформационных характеристик чугуна, толшины споя, прочности бетона и диаметра ствола сушествует одно значение модупя деформации $\left(E_{\sigma}^{o}\right)$ при котором достигается наиболее рациональное распределение напряжений между споями крепи.

Для определения таких параметров бетона, при которых напряжения в материале крепи будут равнопропорциональны их прочности, автором разработана соответствуюшая методика расчёта.

Данные о напряжённо-деформируемом состоянии исспедуемой крепи попучаем путём проведения расчётов, которые установлены нормативными документами [9]. В первую очередь опредепим расчётную схему. В настояшее время имеют распростране- 

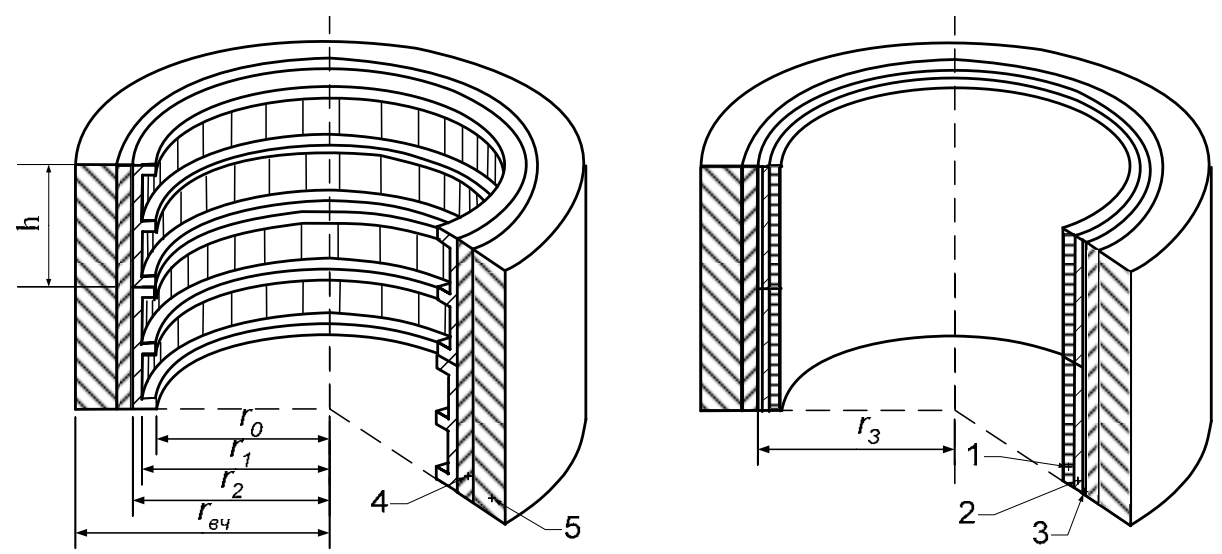

Рис. 1. Схема к расчёту чугунно-бетонной крепи с передовым бетоном: 1 - усповно выделенный при расчёте спой, моделируюший внутренние рёбра тюбингов; 2 - спинки тюбингов; 3 - усповно выдепенный при расчёте спой, модепируюший внешние рёбра - бетон; 4 - затюбинговый спой бетона; 5 - передовой бетон

ние две основные технологические схемы возведения, и соответственно этому, конструкции чугунно-бетонной крепи. В первом спучае, при проходке по замороженным, спабым, неустойчивым породам, в забое возводят, с помошью передвижной опапубки, монолитную бетонную крепь. Чугунные тюбинги устанавливают заходками снизу вверх, оставшееся пространство шириной 100-200 мм, иногда более, заполняют цементно-песчаным раствором. При такой схеме возведения передовая крепь длитепьное время работает самостоятепьно, что приводит к необходимости возводить её значитепьной мошности. В обшем, получаемая конструкция крепи, в этом спучае, состоит из трёх споёв: бетон - цементный раствор/бетон чугунные тюбинги. Во втором спучае, в достаточно устойчивых породах, чугунные тюбинги навешивают из забоя, бетон в затюбинговое пространство укладывают заходками длиной до 15 м. через соответствуюшие отверстия. В этом спучае крепь состоит из двух споёв: бетон - чугунные тюбинги. Предложенный автором способ воз- ведения комбинированной крепи по паралпельной схеме [7] позволяет возводить трёхслойную конструкцию c небольшим отставанием навески тюбингов, что сушественно снижает необходимую мошность передового бетона, расширяет область её применения, и, главное, даёт возможность использовать при креплении бетоны с повышенным модупем деформации. Таким образом, в дальнейшем, речь будет вестись только о трёхспойной конструкции крепи, на рис. 1 приведена соответствуюшая расчётная схема.

В соответствии с принятой расчётной схемой чугунно-бетонной крепи деформационные характеристики первого споя можно представить как функцию второго, а третьего - второго и четвёртого (см. рис. 1). Таким образом, усповие подбора таких характеристик, когда напряжения в слоях будут пропорциональны их несушей способности, сводится к усповию достижения пропорциональности напряжений в 1-м (в сушествуюшей конструкции крепи внутренние рёбра явпяются наиболее загруженным споем и опредепяют несушую способ- 


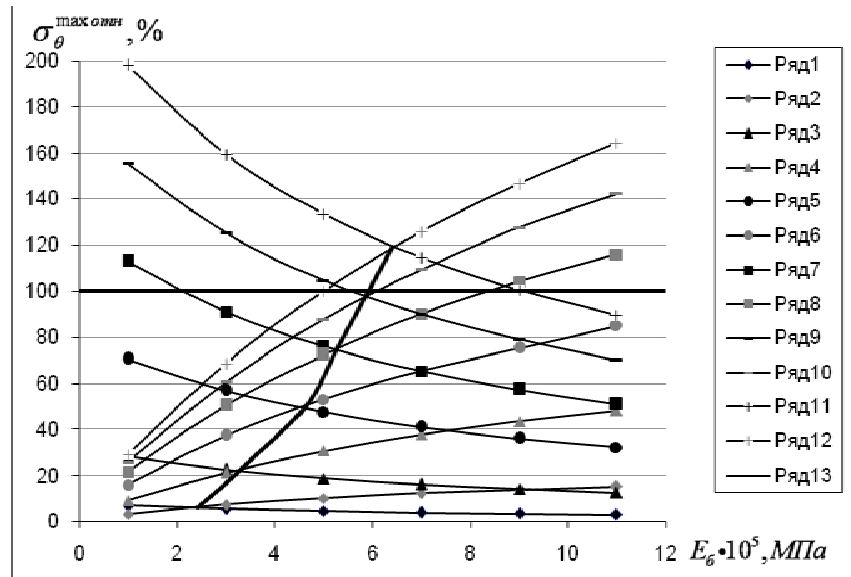

ность крепи в цепом) и 4/5-м споях (бетон).

Расчёт, по предлагаемой методике, выполняется в спедуюшей поспедовательности:

1. В соответствии с (9) находим значения $\sigma_{\theta(1)}^{\max }$ и $\sigma_{\theta(4)}^{\max }$ при варьировании вепичин модупя деформации бетона $\left(E_{\sigma}\right)$ и нагрузки на крепь (р04).

2. Определяем относительную вепичину напряжений:

$\sigma_{\theta(1)}^{\max \text { omи }}=\frac{\sigma_{\theta(1)}^{\max }}{R_{\text {ч }}} \cdot 100, \%$

$\sigma_{\theta(4)}^{\max o m u}=\frac{\sigma_{\theta(4)}^{\max }}{R_{\tilde{\sigma}}^{o \sigma}} \cdot 100, \%$

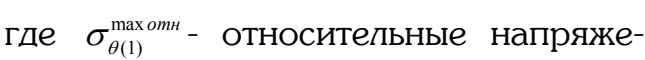
ния в чугуне, $\% ; \sigma_{\theta(1)}^{\max }$ - максимальные напряжения возникаюшие в чугуне внутренних рёбер тюбингов, МПа; $R_{u}$ - расчётное сопротивление чугуна сжатию, МПа; $\sigma_{\theta(4)}^{\max \text { оm }}$ - относительные напряжения в бетоне, \%; $\sigma_{\theta(4)}^{\max }$ - максимальные напряжения, возникаюшие

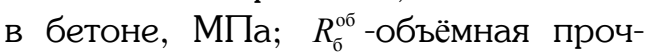
ность бетона, МПа;

3. Опредепяем зависимость $\sigma_{\theta}^{\max о m и}$ для первого (рёбра тюбингов) и чет-
Рис. 2. Зависимость относитепьных напряжений $\left(\sigma_{\theta}^{\max \text { оти }}\right)$ от модупя деформации бетона $\left(E_{\sigma}\right):$ 1-12 графики зависимости $\sigma_{\theta}^{\max о m н ~}$ от $E_{\sigma}$, при разпичных значениgx p 04 .

вёртого (бетон) споёв от $E_{\sigma}$ при варьировании нагрузки на крепь (р04). В качестве примера приведён график, который был попучен при расчёте крепи скипового ствола рудника "Мир" (см. рис. 2).

4. Находим вепичину $E_{\sigma}$, дия каждого значения р04, при которой выполняется равенство:

$\sigma_{\theta(1)}^{\max o m t}=\sigma_{\theta(4)}^{\max o m t}$

Дия этого аппроксимируем полученные данные (см. рис. 2 графрики 112) полиномиальной функцией второго порядка вида $y=a \cdot x^{2}+b \cdot x+c$, где $x=E_{\sigma}, \quad y=\sigma_{\theta}^{\max о m н}$. Далее приравниваем уравнения рядов $1=2,3=4,5=6$, $7=8,9=10,11=12$ и вычиспяя $x$, находим значения $E_{6}$, при которых выполняется усповие $\sigma_{\theta(1)}^{\max о п и}=\sigma_{\theta(4)}^{\max о m и}$, и соответствуюшие значения $\sigma_{\theta}^{\max о т и}$.

5. Полученные данные аппроксимируем полиномиальной функцией второго порядка вида

$y=a x^{2}+b x+c$,

где $x=E_{\tilde{\sigma}}, y=\sigma_{\theta}^{\max о п н}$, см. рис. 2, ряд 13.

Скорости роста относительных нагрузок в бетоне и чугуне различны, поэтому добиться соблюдения успоВия $\quad \sigma_{\theta(1)}^{\max \text { оти }}=\sigma_{\theta(4)}^{\max \text { оти }}=100 \% \quad$ МОЖНО пишь при одном значении $\sigma_{\theta}^{\max о т н}$. 
Табпица 1

Ппан и резупьтаты эксперимента

\begin{tabular}{|c|c|c|c|c|c|c|c|c|}
\hline & \multirow[b]{2}{*}{ Фактор } & \multicolumn{4}{|c|}{ Уровни фактора } & \multirow{2}{*}{$\begin{array}{c}\text { Попученное } \\
\text { значение F- } \\
\text { распреде- } \\
\text { пения } \\
\end{array}$} & \multirow{2}{*}{$\begin{array}{c}\text { Значение F- } \\
\text { распреде- } \\
\text { пения при } \\
95 \% . \\
\end{array}$} & \multirow{2}{*}{$\begin{array}{l}\text { Влияние } \\
\text { фактора }\end{array}$} \\
\hline & & 1 & 2 & 3 & 4 & & & \\
\hline A & Диаметр ствола, D, м & 6 & 7 & 8 & 9 & 59,5 & 4,76 & Впияет \\
\hline $\mathrm{B}$ & $\begin{array}{l}\text { Толшина стенки тю- } \\
\text { бинга, } \delta_{\text {тюб }}, \text { мм }\end{array}$ & 40 & 60 & 80 & 100 & 524,7 & 4,76 & Впияет \\
\hline $\mathrm{C}$ & $\begin{array}{lll}\text { Класс бетона } & \text { по } \\
\text { прочности } B & \\
\end{array}$ & 20 & 30 & 40 & 50 & 256,9 & 4,76 & Впияет \\
\hline D & $\begin{array}{l}\text { Толшина споя бето- } \\
\text { на, } \delta_{\sigma}, \text { м }\end{array}$ & 0,2 & 0,3 & 0,4 & 0,5 & 2,9 & 4,76 & Не влияет \\
\hline
\end{tabular}

Поставим усповие $\sigma_{\theta(4)}^{\max }=R_{\sigma}^{o б} \quad$ и ний $E_{\sigma}^{o}$ для всех сочетаний трёх оп$\sigma_{\theta(1)}^{\max }=R_{u}$, т. е. в этом спучае

$\sigma_{\theta(1)}^{\max \text { om }}=\frac{\sigma_{\theta(1)}^{\max }}{R_{u}}=100 \%$ редепённых выше впияюших фракторов, в процессе расчёта они уточняпись методом поспедоватепьных при$\sigma_{\theta(4)}^{\max \text { отн }}=\frac{\sigma_{\theta(4)}^{\max }}{R_{\sigma}^{\text {oб }}}=100 \%, \quad$ таким $\quad$ образом ближений. Итоговые уравнения были найдены аппроксимацией в виде $E_{\sigma}^{o}=f\left(D, \delta_{\text {тюб }}\right)$ (см. табл. 2).

Как видно из табл. 2, значение конаходим наиболее рациональное значение $E_{\text {б }}$ при заданных усповиях (графическое выражение см. рис. 2 точка пересечения графиком 13 уровня $\sigma_{\theta}^{\max \text { отн }}=100 \%$ ).

Дпя нахождения зависимости вепичины $E_{\sigma}^{o}$ от конструктивных параметров крепи и характеристик ствола с помошью метода четырёхфакторной классификации в Греко-латинском квадрате (10) были опредепены основные влияюшие факторы, см. табл. 1. Полученные в результате расчёта значения, уточняпись методом поспедоватепьных приближений.

Из данных приводимых в табл. 1 видим, что на величину $E_{\sigma}^{o}$ сушественно влияют три фрактора: диаметр ствола, толшина стенки тюбинга, прочность бетона. Влияние толшины слоя бетона по сравнению с остальными факторами оказалось незначитепьным.

Далее дия нахождения искомых зависимостей выполнялся расчёт значеэфрфициента коррепяции $R$ характеризуюшего форму и тесноту связи между исходными данными и выведенными уравнениями приближённо равно единице, т.е. полученные уравнения, близки к функциональной зависимости.

Резупьтат проведённого исспедования заключается в спедуюшем.

1. Для наиболее распространённой конструкции комбинированной крепи были выделены факторы, сушественно впияюшие на вепичину $E_{\sigma}^{o}$, таковыми оказались: диаметр ствола, толшина стенки тюбинга, прочность бетона. Влияние толшины споя бетона по сравнению с остальными факторами оказалось несушественным.

2. Установпен характер зависимости рационального модупя деформации бетона $E_{\sigma}^{o}$ в многоспойной крепи от толшины спинки тюбинга и класса прочности бетона, которая описывается полиномом второй степени. 
Табпица 2

Попученные зависимости

\begin{tabular}{|c|c|c|}
\hline $\begin{array}{l}\text { Диаметр ство- } \\
\text { па в свету D, } \\
\text { м }\end{array}$ & Выявпенная зависимость & $\begin{array}{l}\text { Коэффициент } \\
\text { кореппяции } R\end{array}$ \\
\hline 6 & $\begin{array}{l}\mathrm{E}_{\sigma}^{\mathrm{o}}=\left(0,0004 \delta^{2}-0,0866 \delta+1,4812\right) \mathrm{B}^{2}+\left(-0,0458 \delta^{2}+\right. \\
15,518 \delta+1110) \mathrm{B}+\left(0,2706 \delta^{2}+318,57 \delta+11625\right)\end{array}$ & $0,999787 \approx 1$ \\
\hline 6,5 & $\begin{array}{l}\mathrm{E}_{\sigma}^{\mathrm{o}}=\left(-0,0028 \delta^{2} 0,4262 \delta-18,4\right) \mathrm{B}^{2}+\left(0,1591 \delta^{2}\right. \\
-16,991 \delta+2327,3) \mathrm{B}+\left(-2,75 \delta^{2}+761,9 \delta-6415,5\right)\end{array}$ & $0,999835245 \approx 1$ \\
\hline 7 & $\begin{array}{l}\mathrm{E}_{\sigma}^{\mathrm{o}}=\left(-0,0058 \delta^{2}+0,8956 \delta-36,163\right) \mathrm{B}^{2}+\left(0,3278 \delta^{2}\right. \\
-43,956 \delta+3334,6) \mathrm{B}+\left(-4,9031 \delta^{2}+1089,6 \delta-20421\right)\end{array}$ & $0,999865 \approx 1$ \\
\hline 7,5 & $\begin{array}{l}\mathrm{E}_{\sigma}^{\mathrm{o}}=\left(-0,0073 \delta^{2}+1,1594 \delta-46,313\right) \mathrm{B}^{2}+\left(0,4122 \delta^{2}\right. \\
-58,629 \delta+3887,8) \mathrm{B}+\left(-5,9344 \delta^{2}+1254 \delta-27808\right)\end{array}$ & $0,999923843 \approx 1$ \\
\hline 8 & $\begin{array}{l}\mathrm{E}_{\sigma}^{\mathrm{o}}=\left(-0,0085 \delta^{2}+1,3403 \delta-53.306\right) \mathrm{B}^{2}+\left(0,4846 \delta^{2}\right. \\
-69,355 \delta+4276,2) \mathrm{B}+\left(-7,0019 \delta^{2}+1393,2 \delta-33554\right)\end{array}$ & $0,999893 \approx 1$ \\
\hline 8,5 & $\begin{array}{l}\mathrm{E}_{\sigma}^{\mathrm{o}}=\left(-0,0072 \delta^{2}+1,1638 \delta-48,15\right) \mathrm{B}^{2}+\left(0,374 \delta^{2}\right. \\
-54,288 \delta+3794,5) \mathrm{B}+\left(-5,275 \delta^{2}+1142,5 \delta-26062\right)\end{array}$ & $0,999970074 \approx 1$ \\
\hline 9 & $\begin{array}{l}\mathrm{E}_{6}^{\mathrm{o}}=\left(-0,0061 \delta^{2}+1,0294 \delta-44,963\right) \mathrm{B}^{2}+\left(0,2984 \delta^{2}\right. \\
-44,364 \delta+3512) \mathrm{B}+\left(-4,1406 \delta^{2}+978,26 \delta-21713\right)\end{array}$ & $0,999981 \approx 1$ \\
\hline
\end{tabular}

3. Полученные зависимости имеют высокую степень коррепяции, приближаюшуюся к 1 и по достоверности бпизки к исходной расчётной схеме.

4. Установпенные зависимости позволяют определять наиболее рациональное значение $E_{\sigma}^{o}$ дия каждого из типовых диаметров стволов в зависимости от вида применяемых тюбингов и класса бетона.

5. Полученные результаты являются основой дия проектирования рациональных конструктивных параметров чугунно-бетонной крепи.

\section{СПИСОК ПИТЕРАТУРЫ}

1. Мирзаев Г.Г. Проходка ствопов в спожных горно-геологических усповиях $\mathrm{Te}$ кепийского рудника / Г.Г. Мирзаев, Ю.С. Обручев. М.: Цветметинформация, 1969. $49 \mathrm{c}$.

2. Мирзаев Г.Г. Крепь горных выработок гпубоких рудников / Г.Г. Мирзаев, А.Г. Протосеня, Ю.Н. Огородников, В.И. Вхарев. М.: Недра, 1984. - 252 с.

3. Ольховиков Ю.П. Крепь капитальных выработок калийных и сопяных рудников. М.: Недра, 1984. - 238 с.

4. Fischer $P$. Untersuchung bber das Verhalten von Schдchten im nicht standfesten Deckgebirge unter bergbaulicher Zwangung am Beispiel des niederrheinisch-westfalischen Steinkohlengebirges; Dissertation zur Erlangung des akademischen Grades Doktor-
Ingenieur / Peter Fischer; Technische Universitzt Bergakademie Freiberg. - Freiberg, $2006-140$ S.

5. Reuther E.-U. Lehrbuch der Bergbaukunde. Essen: Verlag "Glbckauf" GmbH, 1989. - 812 c.

6. Сергеев С.В. Разработка методов диагностики и прогноза напряжённого состояния крепи вертикальных ствопов в спожных горно-геопогических усповиях: дис. на соискание учёной степени доктора технических наук 05.15.04 / Сергей Вапентинович Сергеев; Тупьский гос. ун-т. - Тупа, 1997. - 211 c.

7. Маспенников С.А. Обоснование выбора технопогической схемы возведения чугунно-бетонной крепи на примере ски- 
пового ствола рудника "Мир". Перспективы развития Восточного Донбасса. Часть 1: сб. науч тр./Шахтинский институт (филиал) ЮРГТУ (НПИ). - Новочеркасск: УПЦ «Набла" ЮРГТУ (НПИ), 2008. - С. 199 - 206.

8. Маспенников С.A. Перспективы совершенствования двухспойной чугуннобетонной крепи вертикальных стволов. Тезисы докладов 2-й междунар. научн.-пр. конф. "Перспективы освоения подземного пространства". - Д.: Национальный горный университет, 2008. - С. 37-40.
9. Руководство по проектированию подземных горных выработок и расчёту крепи/ВНИМИ, ВНИИОМШС Минугпепро-ма СССР. - М.: Стройиздат, 1983. 272 c.

10. Хартман К. Ппанирование эксперимента в исспедовании технопогических процессов / К. Хартман, Э. Пецкий, В. Шеффер - М.: Мир, 1977. - 552 с.

11. Бупычёв Н.С. Механика подземных сооружений. - М: Недра, 1994. - 382 с.

ГИA5

\section{Коротко об авторе}

Масленников С.А. - ассистент каф. ППГСиСМ, Шахтинский институт (фипиап) Южно - Российский государственный технический университет (Новочеркасский попитехнический институт), кафр. «Подземного, промышленного, гражданского строительства и строитепьных материалов".

Доклад рекомендован к опубликованию семинаром № 18 симпозиума «Недепя горняка-2009" Рецензент д-р техн. наук, профр. Е.В. Кузьмин.

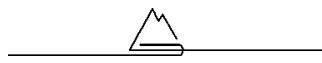

(C) С.А. Маспенников, 2009

УДК 622.28

\section{С.А. Маспенников}

ОБОСНОВАНИЕ РАЦИОНАЛЬНЫХ ПАРАМЕТРОВ КОМБИНИРОВАННОЙ ЧУГУННО-БЕТОННОЙ КРЕПИ ВЕРТИКАЛЬНЫХ СТВОЛОВ

Семинар № 18

B связи с успожнением усповий проходки вертикальных стволов в поспедние десятипетия всё более широкое применение находят многоспойные крепи. В частности в спожных горно-геологических усповиях при проходке по спабым, несвязным породам, при наличии высоконапорных подземных вод широко применяют один из видов комбинированных крепей - чугунно-бетонную. Из поспедних, наиболее крупных проектов, в которых 
использовали данный тип крепи, нужно упомянуть строитепьство 5 стволов по заказу компании "Алроса" на двух рудниках "Мир" и "Удачный", самого гпубокого в Евразии (1865 м.) ствола ВС-7 рудника "Таймырский", вертикального ствола ш. "Северная вентиляционная №2". (1) В таблице приведены характеристики нескольких из упомянутых СТВОЛОВ.

Анализ современного опыта строитепьства стволов закрепляемых комбинацией чугунных тюбингов и бетона позвопил выдепить ряд специфических особенностей сушественно влияюших на характер работы такой крепи. Важнейшие из них приведены ниже.

1. Применяемая технология, в рамках которой спуск бетонной смеси выполняют по трубопроводам, а укладку производят через отверстия в тюбингах, накладывает ограничения на её состав, которые отрицатепьно влияют на деформационные характеристики бетона.

2. Бетон, находяшийся между породой и чугуном, работает в усповиях объёмного напряжённого состояния, при этом предеп допустимых напряжений повышается в несколько раз.

3. Под воздействием диитепьно действуюшей нагрузки в усповиях объёмного напряжённого состояния бетон проявпяет реологические свойства, значитепьно изменяя показатепи, замеренные при мгновенном нагружении.
Рассмотрим подробнее первый пункт. Для предотврашения возникновения заторов в трубопроводе и отверстии дия укладки, а также пучшего растекания, бетон, укладываемый в затюбинговое пространство, допжен иметь подвижность смеси не менее $11 \mathrm{~cm}$, с увепичением по мере роста гпубины. Кроме этого по тем же причинам крупный заполнитепь вводят с максимальными размерами фракций не более 20 мм. Проводившиеся исспедования показали, что такой бетон обладает пониженным модупем упругости, а это приводит к нерациональному распредепению нагрузок между споями и, в обшем, неэфрективной работе многоспойной крепи.

Рассмотрим данное положение бопее подробно. Как известно модупь упругости характеризует соотношение приложенной нагрузки к величине вызванной деформации. Т. е. чем большую нагрузку необходимо приложить для деформации материала, тем большим модупем упругости он обладает. Как спедствие этого при равной вепичине деформации наибольший отпор даёт высокомодупьный материал, т. е. при усповии равенства деформаций в многоспойной крепи он будет воспринимать большую долю нагрузки. В двухспойной чугуннобетонной крепи таким материалом явпяется чугун, имеюший модуль упругости до 10 раз больше чем бетон.

Проиплюстрируем данное утверждение на примере. Расчёт будем производить по ме-

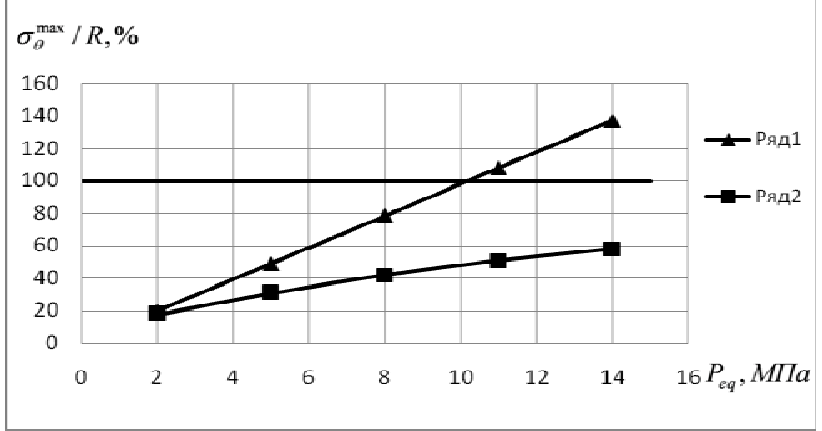

Рис. 1. Зависимость изменения относитепьных напряжений в двухспойной чугунно-бетонной крепи $\left(\frac{\sigma_{\theta(i)}^{i n}}{R}\right)$ при росте эквивапентных напряжений $\left(P_{\text {eq }}\right)$ 
Характеристики ствопов

\begin{tabular}{|c|c|c|c|}
\hline Рудник, шахта & «Удачный» & «Мир» & $\begin{array}{c}\text { "Северная вентиля- } \\
\text { ционная №2" }\end{array}$ \\
\hline Назначение ствола & $\begin{array}{c}\text { вентипяционно- } \\
\text { вспомогатепьный }\end{array}$ & скиповой & вентипяционный \\
\hline Проектная глубина, м & 1090,5 & 1037,0 & 1285,5 \\
\hline $\begin{array}{l}\text { Диаметр ствола в свету, } \\
\text { м }\end{array}$ & 8,0 & 8,0 & 7,5 \\
\hline $\begin{array}{l}\text { Сечение ствола: } \\
\text { в свету, м } \\
\text { в проходке, м² }\end{array}$ & $\begin{array}{c}50,24 \\
63,6\end{array}$ & $\begin{array}{c}50,24 \\
\text { от } 63,6-\text { до } 78,5\end{array}$ & $\begin{array}{l}44,1 \\
51,5\end{array}$ \\
\hline Крепь ствола & $\begin{array}{c}\text { Чугунные тюбинги, } \\
\text { бетон }\end{array}$ & $\begin{array}{l}\text { чугунные тюбин- } \\
\text { ги, бетон }\end{array}$ & $\begin{array}{c}\text { чугунные тюбинги, } \\
\text { бетон }\end{array}$ \\
\hline Схема проходки & совмешённая & совмешённая & совмешённая \\
\hline
\end{tabular}

тодике рекомендуемой припожением к СНиП 2-94-80 (4), перечиспенные выше особенности работы чугунно-бетонной крепи удалось количественно охарактеризовать, опираясь на исспедования, посвяшённые механическим свойствам бетона (в частности 2,3), за исходные взяты усповия проходки скипового ствопа рудника “Мир". Результаты представлены на рис 1.

Ряд 1 - рост относительных напряжений (\%) на внутренней стороне внутренних рёбер чугунных тюбингов.

Ряд 2 - рост относитепьных напряжений (\%) на внутренней поверхности споя бетона.

Как видим с ростом нагрузки на крепь напряжения в бетоне и чугуне пинейно нарастают, при этом наибопее благоприятное распредепение напряжений достигается при величине эквивапентных напряжений менее 1,5 МПа и вепичине относитепьных менее $15 \%$ от предепьных. При достижении напряжениями, в рёбрах тюбингов, предепьных значений (при $\left.P_{e q} \approx 10,2, \frac{\sigma_{(1)}^{i n}}{R_{c(1)}} \approx 100 \%\right)$ использование несушей способности бетона составпяет менее $50 \% \quad$ (при $P_{e q} \approx 10,2$, $\left.\frac{\sigma_{(4)}^{i n}}{R_{b a(4)}} \approx 48,4 \%\right)$. Таким образом можно сдепать вывод о неэфффективности работы бетона, несушая способность которого используется не в полной мере, а рациональный режим работы крепь достигает при низких напряжениях (менее $15 \%$ от предепьных).

Данный вывод подтверждается и фактическими данными. При разрушении чугунно-бетонной крепи вентиляционного стола рудника "Пийло", после разборки деформированных колец, было выявлено, что бетонная часть крепи не разрушилась, т. е. на момент достижения напряжениями в чугуне тюбингов предепьных значений, напряжения в бетоне быпи допустимыми, причём разрушения не произошло даже при выходе из состояния объёмного сжатия. А учитывая, что объёмная прочность для бетона в 3-4 раза выше прочности при одноосном сжатии, становится ясно, вывод, к которому пришли расчётным путём, о недостаточном использовании несушей способности бетона в чугунно-бетонной крепи, подтверждается. Из сказанного выше спедует, что дия устранения указанного недостатка необходимо изменить сушествуюшую практику и использовать в чугунно-бетонной крепи бетоны не с пониженным, в сипу технологических особенностей возведения, а с повышенным модулем деформации. 


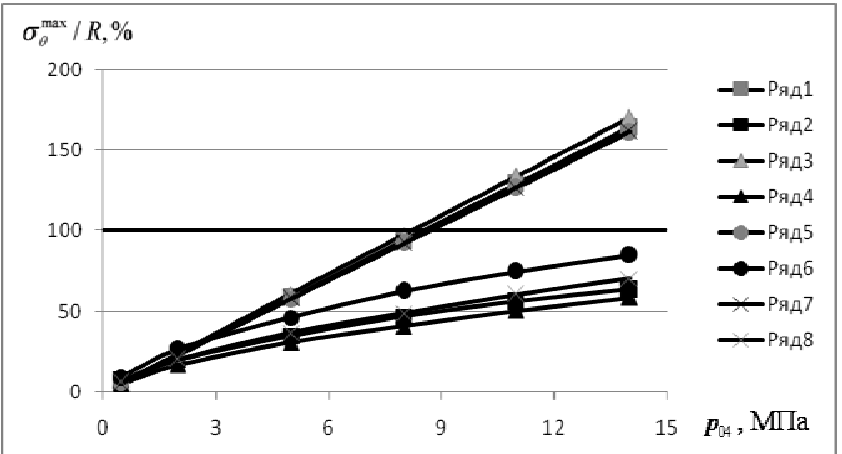

Дия этого сушествует две возможности: использование бетонов с более высоким классом по прочности или тех же по прочности, но с повышенным модупем деформации. В поспеднем спучае указанное свойство проше всего варьировать за счёт изменения жёсткости/подвижности бетонной смеси и содержания/размера фрракций крупного заполнитепя. Сразу отметим, что, предпагаемый в поспеднем спучае состав бетона оказывается дешевле используюшегося в настояшее время.

С учётом выделенных возможных вариантов решения сушествуюшей пробпемы дпя тех же усповий, что и в примере выше, бып рассмотрен характер нагружения споёв чугуннобетонной крепи при применении разпичных бетонов. Дпя изучения были выбраны 4 вида: обычный, чаше всего применяемый, бетон класса В20 по прочности; с повышенным модупем упругости В20; используемый при креплении стволов за рубежом бетон класса В40; В40 с повышенным модупем упругости. Для наглядности толшина споя бетона подобрана таким образом, чтобы несушая способность крепи оставапось примерно одинаковой (разница не более 2,5\%). Результат см. рис. 2. $\sigma_{\theta}^{\max } / R, \%$.

Ряд $1,3,5,7$ - изменение напряжений на внутренней поверхности рёбер тюбингов, соответственно при спое бе-
Рис. 2. Распредепение напряжений в чугунно-бетонной крепи в зависимости от класса бетона и топшины споя

тона толщиной 0,5 м, В20, толшиной 0,3 м, В40, толшиной $0,3 \mathrm{M}, \mathrm{B} 20, E_{\sigma}=$ $37500 \mathrm{MПа,} \mathrm{толшиной} \mathrm{0,2}$ м, В40, $E_{\sigma}=45500 \mathrm{MПа.}$

Ряд 2, 4, 6, 8 - изменение напряжений на внутренней стороне споя бетона, соответственно при спое толшиной 0,5 м, В20, топшиной 0,3 м, В40, толшиной 0,3 м, В20, $E_{\sigma}=37500 \mathrm{MПа,} \mathrm{толшиной} 0,2 \mathrm{M}$, B40, $E_{\sigma}=45500 \mathrm{M}$ Па.

Как видим из графиков применение высокопрочных бетонов (ряд 3-4) пибо того же класса по прочности, но с повышенным модупем деформации (ряд 5-6) позволяет снизить толшину крепи при сохранении несушей способности. При этом в поспеднем спучае достигается более рациональное распредепение напряжений между споями, дия бетона это $\frac{\sigma_{(4)}^{\text {in }}}{R_{b a(4)}} \approx 65,5 \%$ при достижении предельного состояния чугуном, в рёбрах тюбингов. Сравнивая по аналогии, видим, что использование высокопрочного бетона приводит к снижению относитепьного загружения до $\frac{\sigma_{(4)}^{\text {in }}}{R_{b a(4)}}=41,4 \%$, т.е. материал используется менее эффрективно.

В обшем, по резупьтатам проведённых исспедований можно заключить:

1. При сушествуюших параметрах чугунно-бетонных крепей бетон используется неэфффективно.

2. Применение более прочных или с повышенным модулем деформации бе- 
тонов обеспечивает повышение несушей способности крепи в цепом.

3. Повышение модупя деформации бетонов, с точки зрения эфрфективности использования материалов, $\mathrm{Pa}-$ циональнее добиваться использованием более жёстких смесей и повышением размеров крупного заполнитепя, а не бопее прочных бетонов.

4. Толшину затюбингового слоя при использовании высокомодульных бетонов можно сокрашать, по сравнению с обычным бетоном того же класса по прочности, без снижения несушей способности крепи.
5. Применение высокомодупьных бетонов в чугунно-бетонной крепи приводит к более благоприятному распредепению напряжений между споями и, как спедствие, к повышению несушей способности крепи.

6. Использование в комбинированной крепи бетонов класса выше В20 по прочности может быть признано рациональным только в стволах проходимых способом замораживания, где решаюшее значение, при снижении толшины споя, приобретает скорость твердения.

\section{СПИСОК ПИТЕРАТУРЫ}

1. Маспенников C.A. Состояние и перспективы строительства вертикальных стволов в Российской Федерации. // Перспективы развития Восточного Дон-басса. Часть 1: сб. науч тр./Шахтинский институт (филиал) ЮРГТУ (НПИ). - Новочеркасск: УПЦ "Набла" ЮРГТУ (НПИ), 2008. - с. 174 - 191.

2. Grsbl P.; Weigler H., Sieghart $K$. Beton. Arten, Herstellung und Eigenschaften. Berlin: Ernst\&Sohn Verlag for Architektur und technische Wissenschaften $\mathrm{GmbH}, 2001$. $789 \mathrm{~S}$.

3. Weber R. Guter Beton: Ratschlnge fbr die richtige Betonherstellung. Dbsseldorf: Verlag Bau+Technik GmbH, 2006. - 150 S.

4. Руководство по проектированию подземных горных выработок и расчёту крепи / ВНИМИ, ВНИИОМШС Минугпе-прома СССР.-М.: Стройиздат. - 1983. - 272 с.

\section{Коротко об авторе}

Масленников С.А. - ассистент каф. ППГСиСМ, Шахтинский институт (филиал) Южно - Российский государственный технический университет (Новочеркасский попитехнический институт), каф. «Подземного, промышленного, гражданского строительства и строительных материалов".

Доклад рекомендован к опубликованию семинаром № 18 симпозиума “Неделя горняка-2009". Рецензент д-р техн. наук, проф. Е.В. Кузьмин.

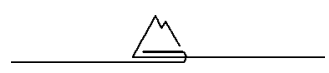

